\title{
INCORPORAÇÃO E AVALIAÇÃO DA CINÉTICA DE LIBERAÇÃO DO COMPOSTO NATURAL ALFA-BISABOLOL EM FILMES DE POLICAPROLACTONA E DE QUITOSANA COMPLEXADA COM GOMA GUAR
}

\author{
FERNANDA. C. B. de SOUZA, RENATA. F. B. de SOUZA e ÂNGELA. M. MORAES \\ Universidade Estadual de Campinas, Faculdade de Engenharia Química, \\ Departamento de Engenharia de Materiais e Bioprocessos \\ E-mail para contato: ammoraes@feq.unicamp.br
}

\begin{abstract}
RESUMO - A quitosana (Q), a goma guar (G) e a policaprolactona (PCL) são polímeros usados na obtenção de curativos para a pele por serem biocompatíveis e biodegradáveis. Para aumentar a atividade biológica destes curativos, a incorporação de compostos bioativos que estimulam a cura das lesões de pele pode ser feita. Neste contexto, este trabalho visou à incorporação do composto natural alfa-bisabolol a filmes de PCL e de Q complexada com G (Q-G). Os filmes obtidos foram caracterizados quanto ao seu aspecto visual e morfologia e a eficiência de incorporação do alfa-bisabolol, bem como sua cinética de liberação dos filmes, foram estudadas. Os resultados mostraram que houve alteração significativa do aspecto e morfologia dos filmes com a incorporação do composto ativo. Devido à limitada compatibilidade entre o alfa-bisabolol, de caráter hidrofóbico, e os filmes de Q-G, de caráter hidrofílico, a eficiência de incorporação foi baixa (entre $0,6 \%$ e $18 \%$ ). No caso da PCL, no entanto, eficiência de incorporação de $100 \%$ foi observada. A liberação mostrou-se lenta em ambos os casos e a porcentagem máxima de alfa-bisabolol liberada ficou em torno de $6 \%$ e $30 \%$ para filmes de PCL e de Q-G, respectivamente. Esta liberação de forma lenta permite que os sistemas sejam utilizados como reservatórios do composto ativo por grandes períodos, o que sugere que seria possível que a troca do curativo fosse realizada com intervalos de tempo maiores, tornando o tratamento menos incômodo para o paciente.
\end{abstract}

\section{INTRODUÇÃO}

A pele é o maior órgão do corpo humano, possui estrutura complexa e constitui sua interface com o meio externo, exercendo funções importantes como termorregulação, sensibilidade e barreira de proteção mecânica e imunológica (Tortora e Derrickson, 2012). As lesões de pele podem afetar este órgão em diferentes profundidades, comprometendo todas as suas funções. Visando auxiliar, agilizar e melhorar o processo natural de cura de uma lesão utilizam-se os curativos (Franco e Gonçalves, 2008).

Muitas matérias-primas têm sido testadas para a produção destes dispositivos e, devido às suas propriedades funcionais e relativa flexibilidade na sua síntese, os polímeros, tanto de origem natural quanto sintética, são a classe de materiais mais utilizada para a produção de matrizes voltadas para esta aplicação (Ramalingam e Ramakrishna, 2006). A quitosana e a 
goma guar, polímeros de origem natural, e a policaprolactona, polímero de origem sintética, são exemplos de materiais amplamente utilizados na obtenção de produtos para a área médica.

A quitosana é um polímero de origem natural extraído principalmente do exoesqueleto de crustáceos. É biocompatível, biodegradável, bioadesiva e possui propriedades biológicas relevantes, como efeito anti-inflamatório, antibacteriano e hemostático (Croisier e Jérôme, 2013). A goma guar é outro polímero natural, obtido da planta Cyamopsis tetragonolobus. É usada em várias formulações farmacêuticas e tem sido explorada como potencial matriz para liberação controlada de fármacos (Prabaharan, 2011). A quitosana e a goma guar se associam de modo a formar um complexo físico e essa sinergia entre os dois biopolímeros tem sido estudada e aplicada no desenvolvimento de dispositivos médicos (Randhawa et al., 2012; Veiga, 2012). Já a policaprolactona é um polímero sintético e dentre suas principais propriedades destacam-se a biocompatibilidade e biodegradabilidade, além de alta permeabilidade a compostos ativos (Woodruff e Hutmacher, 2010).

A incorporação em curativos de princípios ativos de plantas ou fármacos sintéticos na tem se mostrado uma excelente alternativa no tratamento de ferimentos crônicos, já que o composto incorporado estimula o processo de cura da lesão (Weller e Sussman, 2006). Um exemplo de tipo de composto é o alfa-bisabolol, um álcool sesquiterpênico monocíclico insaturado natural. No Brasil, este composto é majoritariamente extraído da árvore Candeia (Eremanthus erythropappus). Apresenta uma grande variedade de propriedades biológicas, dentre as quais destacam-se seus efeitos antimicrobiano, antifúngico, antiespasmódico, analgésico, antioxidante e anti-inflamatório (Kamatou e Viljoen, 2010; Clark et al., 2011).

Neste contexto, este trabalho teve como objetivo a obtenção de curativos biologicamente ativos, por meio da incorporação do alfa-bisabolol, um composto de origem natural, a filmes constituídos de quitosana combinada com goma guar e de policaprolactona.

\section{MATERIAIS E MÉTODOS}

\subsection{Materiais}

Para a obtenção dos filmes foram utilizados os seguintes reagentes, de qualidade analítica certificada: quitosana de carapaça de camarão com grau de desacetilação mínimo de $75 \%$ (lote $\mathrm{n}^{\mathrm{o}} 061 \mathrm{M} 0046 \mathrm{~V}$ ), goma guar (lote $\mathrm{n}^{\circ} 087 \mathrm{~K} 0128$ ) e policaprolactona de massa molar média de $80 \mathrm{kDa}$ (lote $\mathrm{n}^{\circ} \mathrm{MKBJ} 4388 \mathrm{~V}$ ), fornecidos pela Sigma-Aldrich Co.; ácido acético glacial, etanol e clorofórmio da Synth. O alfa-bisabolol, Albi ${ }^{\circledR}$, com teor mínimo de pureza de 95\%, foi gentilmente doado pela empresa Atina (Ativos Naturais - Pouso Alegre, MG). A água utilizada nos ensaios foi destilada e deionizada em sistema Milli- $\mathrm{Q}^{\circledR}$ da Millipore.

\subsection{Métodos}

Preparação dos filmes: Os filmes de Q-G foram preparados com base nos procedimentos descritos por Veiga (2012), que se fundamentam na formação de um complexo fisicamente associado entre os dois biopolímeros em reator sob temperatura e agitação controladas, seguida da desaeração da mistura, sua moldagem em placa de poliestireno, evaporação do solvente em estufa, lavagem e neutralização do filme formado e finalmente a 
secagem a temperatura ambiente. Já os filmes de PCL foram preparados pela dissolução dos pellets do polímero em $20 \mathrm{~mL}$ de clorofórmio na concentração de $2 \%(\mathrm{~m} / \mathrm{v})$ sob agitação magnética, seguida de sua desaeração, moldagem em placas de vidro e evaporação do solvente em capela a temperatura ambiente. A incorporação do alfa-bisabolol foi feita por adição direta do composto à mistura polimérica $(\mathrm{AD})$ nos filmes de Q-G e de PCL na proporção de $20 \%(\mathrm{~m} / \mathrm{m})$ em relação à massa total de polímeros e por imersão em solução do composto (IE) em uma mistura de água e etanol na proporção de $25: 75 \%$ apenas para os filmes de Q-G, sendo a concentração do composto na solução igual a 1,2;3,0 e 7,5 mg/mL, período de incubação de 1 hora, temperatura de $25^{\circ} \mathrm{C}$ e agitação de $100 \mathrm{rpm}$.

Avaliação do aspecto visual e morfologia dos filmes: Os filmes foram inspecionados a olho nu e seu aspecto foi fotografado com câmera digital (A410, Canon). A morfologia de amostras de $2 \mathrm{~cm} \times 1 \mathrm{~cm}$ armazenadas em dessecador e recobertas com ouro foi avaliada por microscopia eletrônica de varredura (MEV) em microscópio (LEO 440, Leica). Para a avaliação da seção transversal, as amostras foram previamente criofraturadas em $\mathrm{N}_{2}$ líquido.

Eficiência de incorporação: Para a medida da eficiência de incorporação do alfabisabolol nos filmes de Q-G pelo método $\mathrm{AD}$, inicialmente determinou-se a massa dos filmes coletados na íntegra diretamente da placa de poliestireno. Então, amostras de $2 \mathrm{~cm} \mathrm{x} \mathrm{1,5} \mathrm{cm,}$ em triplicata, foram recortadas das membranas e também pesadas. Estas amostras foram incubadas em $5 \mathrm{~mL}$ de etanol por amostra por 1 hora a $25^{\circ} \mathrm{C}$ para a extração do composto incorporado e, a seguir, o alfa-bisabolol presente na solução etanólica remanescente foi quantificado por espectrofotometria de absorção de luz a $208 \mathrm{~nm}$. O mesmo procedimento foi realizado para as amostras que não continham o alfa-bisabolol incorporado à sua estrutura, a fim de se quantificar compostos extratíveis com etanol que não fossem o composto em estudo. Pela diferença entre a massa de composto inicialmente adicionada ao filme $\left(m_{c, i}\right)$ e a massa remanescente na solução, determinou-se a quantidade de alfa-bisabolol retida na amostra e, por relação de massas com o filme íntegro, calculou-se a massa total do composto nele retida $\left(m_{c, f}\right)$. A eficiência de incorporação $(\varepsilon)$ pôde ser então calculada pela Equação 1.

$$
\varepsilon=\frac{m_{C, f}}{m_{C, i}} \times 100 \%
$$

(Equação 1)

Nas membranas de PCL, a eficiência de incorporação pelo método AD foi também calculada de acordo com a Equação 1, sendo $m_{c, f}$ calculada conforme a Equação 2:

$$
m_{c, f}=m_{c, i}-m_{c, p e}-m_{c, p p}
$$

onde: $\mathrm{m}_{\mathrm{c}, \mathrm{i}}$ é a massa inicial de alfa-bisabolol adicionada à formulação, $\mathrm{m}_{\mathrm{c}, \mathrm{pe}}$ é a massa de perdida por evaporação e $\mathrm{m}_{\mathrm{c}, \mathrm{pp}}$ é a massa perdida por retenção na placa de vidro.

Para o cálculo da eficiência de incorporação do alfa-bisabolol incorporado pelo método IE, a quantidade do composto presente na solução etanólica remanescente logo após o fim do período de incubação dos filmes foi determinada por espectrofotometria a $208 \mathrm{~nm}$. Este procedimento foi realizado também para membranas que não continham alfa-bisabolol. Pela diferença entre $m_{c, i}$ e a massa remanescente na solução, determinou-se $m_{c, f}$. A eficiência de incorporação $(\varepsilon)$ foi então calculada pela Equação 1. 
Cinética de liberação: O comportamento de liberação do alfa-bisabolol incorporado foi avaliado em membranas de Q-G e de PCL de $1 \mathrm{~cm} \times 1 \mathrm{~cm}$, em triplicata. No caso das membranas de PCL, os corpos de prova foram pesados e posicionados em suportes de telas de nylon na parte superior de cubetas de quartzo contendo 3,0 mL de tampão PBS sob agitação de $100 \mathrm{rpm}$ e temperatura de $37^{\circ} \mathrm{C}$. Já para as membranas de Q-G, amostras previamente pesadas foram colocadas em frascos agitados a $100 \mathrm{rpm}$ contendo $10 \mathrm{~mL}$ de PBS a $37^{\circ} \mathrm{C}$. O meio de liberação foi periodicamente trocado e analisado quanto à concentração do composto por espectrofotometria a $208 \mathrm{~nm}$.

\section{RESULTADOS E DISCUSSÃO}

No que se refere à eficiência de incorporação do alfa-bisabolol pelo método $\mathrm{AD}$, os valores obtidos foram de 1,33 $\pm 0,34 \mathrm{mg} / \mathrm{g}$ para Q-G e $200 \mathrm{mg} / \mathrm{g}$ para PCL. Sabendo-se que a quantidade de composto inicialmente adicionada $\mathrm{em}$ ambas as formulações foi de $200 \mathrm{mg}_{\text {composto }} / \mathrm{g}_{\text {polímeros }}$, as eficiências de incorporação foram, portanto, de $0,67 \%$ e $100 \%$ para Q-G e PCL, respectivamente. Logo, para a formulação de Q-G, a eficiência de incorporação do alfa-bisabolol foi baixa, indicando baixa afinidade do composto pela matriz polimérica, afinidade esta relacionada ao caráter hidrofílico/hidrofóbico do composto e da matriz, sendo o primeiro hidrofóbico e a segunda, hidrofílica. Grande parte do composto provavelmente foi perdida nas etapas de neutralização e lavagem da membrana, principalmente na neutralização, na qual é adicionado etanol, solvente em que o composto ativo tem alta solubilidade. Já nos filmes de PCL, $100 \%$ do composto adicionado ficou neles retido, não se observando evaporação do alfa-bisabolol nas condições de preparo dos filmes ou sua presença na água de lavagem das placas nas quais os mesmos foram preparados.

As eficiências de incorporação do alfa-bisabolol aos filmes de Q-G por IE para as diferentes concentrações do composto na solução de impregnação são mostradas na Figura 1. Nota-se um aumento significativo da eficiência de incorporação do composto à matriz, bem como da massa de composto retido quando comparado ao método AD. Supõe-se que a água intumesceu a matriz, promovendo a entrada de quantidade significativa da solução de impregnação e acarretando em maior massa de alfa-bisabolol retido nas amostras. Apesar de a eficiência de incorporação não ser muito alta no método IE, tal abordagem resulta na retenção de grandes quantidades do composto nas membranas. Para contornar esta questão, pode-se reaproveitar a solução de impregnação e assim aumentar a eficiência global do processo.

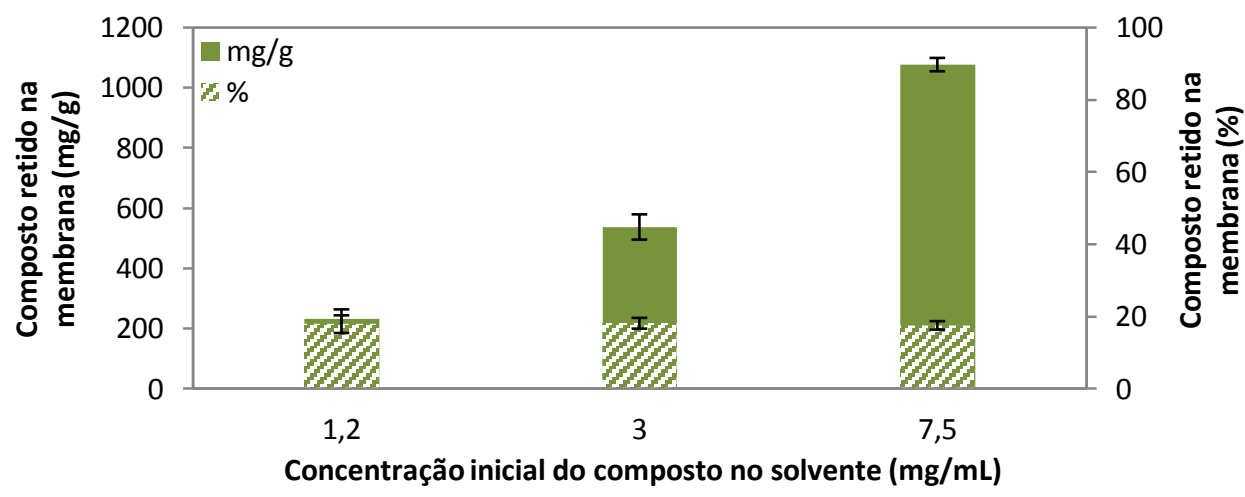

Figura 1: Eficiência de incorporação do alfa-bisabolol aos filmes de Q-G pelo método IE. 
Tendo em vista os resultados apresentados até este ponto, as caracterizações seguintes serão mostradas apenas para as formulações que foram capazes de reter maiores quantidades de alfa-bisabolol, ou seja, filmes de Q-G em que o composto foi incorporado pelo método IE utilizando-se solução de concentração igual a $7,5 \mathrm{mg} / \mathrm{mL}$ e filmes de PCL em que o composto foi incorporado pelo método AD na proporção de $20 \%(\mathrm{~m} / \mathrm{m})$.

$\mathrm{O}$ aspecto típico das membranas de $\mathrm{Q}-\mathrm{G}$ e de PCL isentas de alfa-bisabolol e às quais o composto foi incorporado em quantidade significativa é mostrado na Figura 2.
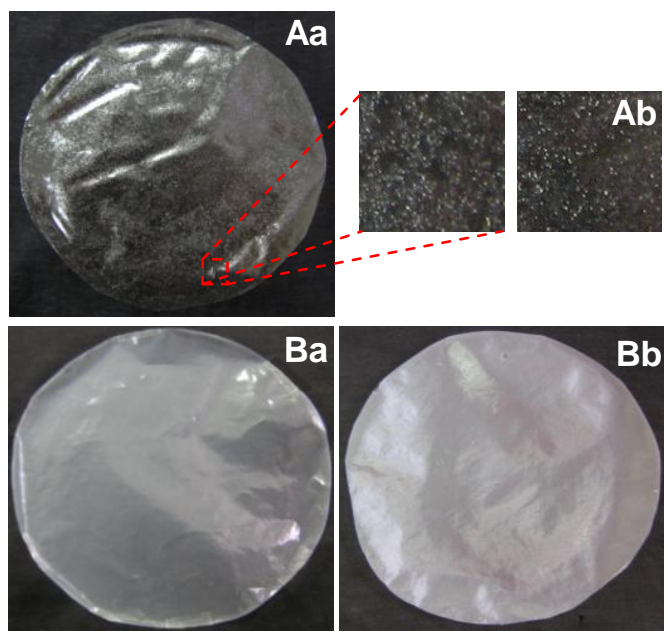

Figura 2: Aspecto visual dos filmes de Q-G (A) e de PCL (B) isentos de alfa-bisabolol (a) e em que o composto foi incorporado (b). Para Q-G, o método de incorporação utilizado foi IE com solução de concentração 7,5 mg/mL e para PCL, utilizou-se o método AD com adição do composto na proporção de $20 \%(\mathrm{~m} / \mathrm{m})$. No detalhe em (Aa) é destacada parte da região do

filme para fins de comparação com (Ab).

Todos os filmes possuem superfície lisa e os filmes de PCL são aparentemente mais opacos que os de Q-G. Para os filmes de PCL, observa-se um pequeno aumento da opacidade com a adição do alfa-bisabolol à matriz. Já no caso de Q-G, apesar de a quantidade de composto retida no filme ser significativamente maior, o aspecto do filme não se alterou em relação àquele em que o composto não havia sido incorporado.

As morfologias da superfície e da seção transversal das amostras de Q-G e PCL contendo ou não alfa-bisabolol são mostradas na Figura 3. Pode-se observar que os filmes de Q-G isentos de alfa-bisabolol possuem em sua superfície algumas irregularidades, porém não são necessariamente rugosos, e sua estrutura é densa e contínua. Já para os filmes Q-G em que se incorporou o alfa-bisabolol pelo método IE, nota-se a presença de pequenas bolhas distribuídas heterogeneamente na superfície, nas quais pode haver alfa-bisabolol alojado. A estrutura permanece densa, assim como a apresentada pela membrana na qual o composto ativo não está presente e não é possível observar a formação de poros na escala analisada. Observa-se que os filmes de PCL isentos de alfa-bisabolol apresentam pequenas saliências na forma de bolhas na superfície, resultantes da rápida evaporação do solvente. A micrografia da seção transversal, por sua vez, revela uma estrutura com múltiplas lamelas. Quanto aos filmes de PCL contendo alfa-bisabolol, nota-se a presença de blocos interconectados decorrentes da exclusão do composto ativo durante a formação da matriz polimérica. A imagem da seção 
transversal sugere que o alfa-bisabolol é direcionado para bolsões presentes no interior da matriz polimérica, onde permanece alojado. Supõe-se que a matriz tende a se formar de maneira a excluir da rede o composto no qual a solubilidade do polímero é baixa, o que ocasiona a formação dos blocos de forma poligonal observados.
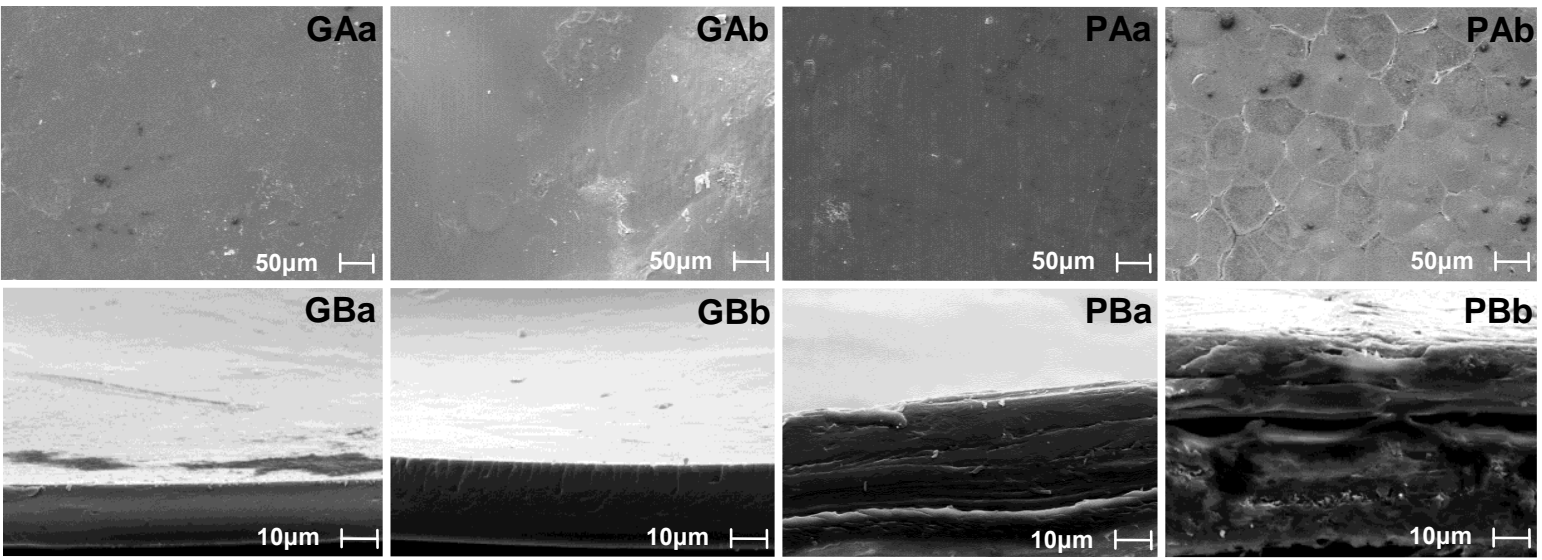

Figura 3: Morfologia da superfície (A) e da seção transversal (B) dos filmes de Q-G (G) e de PCL (P) isentos de alfa-bisabolol (a) e aos quais o composto foi incorporado (b). Para Q-G o método de incorporação utilizado foi IE com solução de concentração $7,5 \mathrm{mg} / \mathrm{mL}$ e para PCL utilizou-se o método AD com adição do composto na proporção de $20 \%(\mathrm{~m} / \mathrm{m})$.

Na Figura 4 são mostrados os resultados da cinética de liberação do alfa-bisabolol para as membranas de PCL. Houve troca do meio de liberação nos tempos de 15 e 48 horas. Observa-se que cerca de $6 \%$ do composto, o equivalente a $12 \mathrm{mg} / \mathrm{g}$, foi liberado em um período de 120 horas. Verifica-se que no início ocorre uma liberação relativamente mais rápida, que possivelmente se deve ao desprendimento do composto mais fracamente associado à matriz, localizado apenas na sua superfície. Já a fração do composto que estava localizada nas camadas mais internas do filme, ou nos bolsões, como visualizado nas micrografias, tem uma liberação lenta, atrasada pelo processo de difusão pela matriz. Além da dificuldade imposta por este processo de difusão, deve-se considerar também o fato de que o alfa-bisabolol é liberado gradativamente em pequenas quantidades devido à grande afinidade do composto pela matriz de PCL, considerando que ambos possuem caráter hidrofóbico.

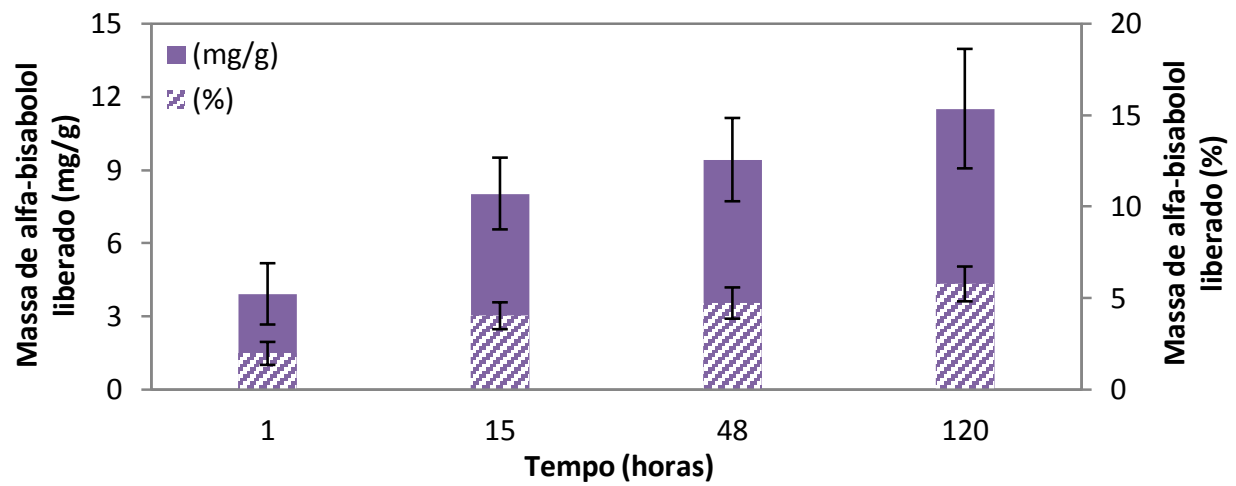

Figura 4: Liberação de alfa-bisabolol incorporado às membranas de PCL por adição direta à mistura polimérica em termos de massa liberada do composto por massa de membrana $(\mathrm{mg} / \mathrm{g})$ e percentagem liberada (\%). A massa inicial do composto retida no filme era de $200 \mathrm{mg} / \mathrm{g}$. 
Na Figura 5 são mostrados os resultados da cinética de liberação do alfa-bisabolol para as membranas de Q-G. O meio de liberação foi trocado a cada 1 hora até o tempo de 4 horas. Observa-se que a percentagem máxima do composto liberada no período estudado ( $48 \mathrm{~h})$, foi de cerca de $30 \%$ do retido, o que equivale a aproximadamente $300 \mathrm{mg} / \mathrm{g}$. A quantidade de alfa-bisabolol liberada, neste caso, é consideravelmente superior àquela observada nos filmes de PCL, tendo em vista que a massa inicialmente retida era também muito maior. Observa-se neste caso um perfil semelhante à liberação do composto das membranas de PCL, no qual há uma liberação de maior quantidade de composto em um menor intervalo de tempo logo no início, seguida de uma liberação mais lenta a partir de determinado ponto. Diferentemente da matriz de PCL, que apresenta uma alta afinidade pelo alfa-bisabolol, a matriz de Q-G é hidrofílica e, portanto, não possui tamanha afinidade pelo composto. No entanto, tendo em vista que esta possui em sua estrutura alguns grupos de natureza hidrofóbica $\left(-\mathrm{CH}_{2},-\mathrm{CH}_{3}\right)$, que tendem a interagir com o alfa-bisabolol, pode-se dizer que o meio de liberação é mais hidrofílico que o filme. Assim, a quantidade de alfa-bisabolol liberada é maior para as membranas de Q-G, porém, ainda não é considerada elevada.

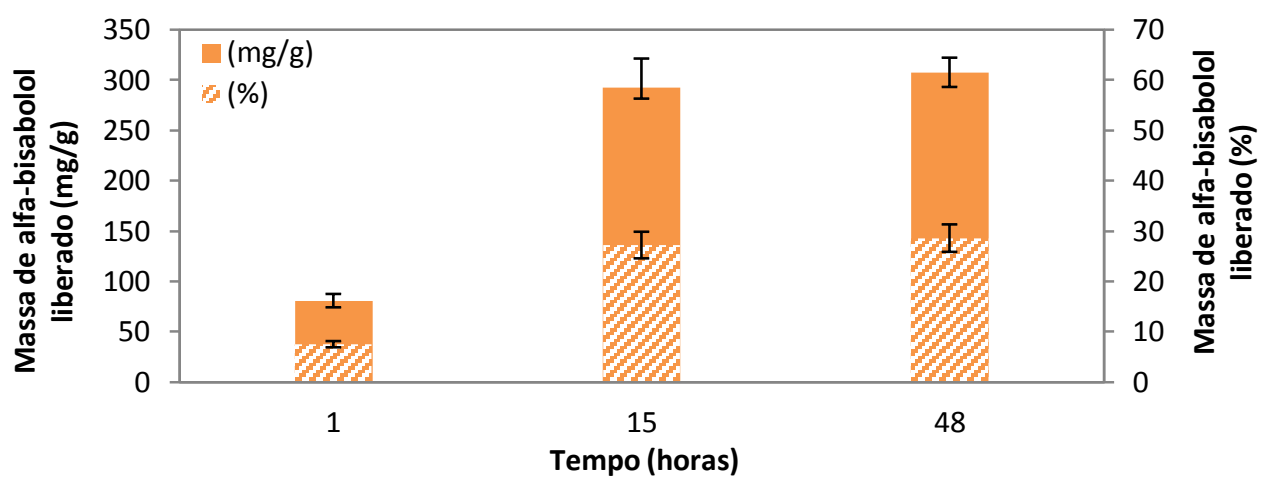

Figura 5: Liberação de alfa-bisabolol incorporado aos filmes de Q-G pelo método IE com solução de concentração $7,5 \mathrm{mg} / \mathrm{mL}$ em termos de massa liberada por massa de membrana (mg/g) e percentagem (\%). A massa inicial do composto retida no filme era de 1076,46 mg/g.

\section{CONCLUSÃO}

Foi possível observar que a introdução do alfa-bisabolol na matriz não alterou o aspecto dos filmes de Q-G, porém os de PCL se tornaram mais opacos. O composto se mostrou heterogeneamente distribuído nas membranas, retido sob bolhas, no caso de Q-G, ou alojado em bolsões no interior da matriz, no caso da PCL. A máxima eficiência de incorporação observada para os filmes de Q-G foi de cerca de $18 \%$, o equivalente a aproximadamente $1 \mathrm{~g} / \mathrm{g}$ quando se utilizou o método IE com solução de concentração $7,5 \mathrm{mg} / \mathrm{mL}$. No caso das membranas de PCL, todo o alfa-bisabolol adicionado ficou retido na estrutura da matriz polimérica. A liberação do composto a partir dos filmes de PCL e Q-G foi considerada lenta, o que pode ser vantajoso uma vez que os sistemas estudados seriam utilizados como reservatórios do composto ativo por um grande período de tempo, requerendo trocas menos frequentes do curativo e trazendo assim mais conforto ao paciente. Considerando que a dosagem do alfa-bisabolol para uso tópico está na faixa de 1 a $10 \mathrm{mg} / \mathrm{g}$, pode-se afirmar que ambas as formulações seriam capazes de liberar esta quantidade do composto e, portanto, podem ser consideradas promissoras para a aplicação proposta. 


\section{REFERÊNCIAS}

Clark, A.; Khweiss, N.; Salazar, L.; Verdadero, L. Promoting sustainability in the value chain of natural bisabolol, a Brazilian rainforest product. School of International and Public Affairs, SIPA at Columbia University, 2011.

Croisier, F.; Jérôme, C. Chitosan-based biomaterials for tissue engineering. Eur. Polym. J., v. 49, p. 780-792, 2013.

Franco, D.; Gonçalves, L. F. Feridas cutâneas: a escolha do curativo adequado. Rev. Col. Bras. Cir., v. 35, n. 3, p. 203-206, 2008.

Kamatou, G. P. P.; Viljoen, A. M. A review of the application and pharmacological properties of $\alpha$-bisabolol and $\alpha$-bisabolol-rich oils. J. Am. Oil Chem. Soc., v. 87, p. 1-7, 2010.

Prabaharan, M. Prospective of guar gum and its derivatives as controlled drug delivery systems. Int. J. Biol. Macromol., v. 49, p. 117-124, 2011.

Ramalingam, M.; Ramakrishna, S. Nano-featured scaffolds for tissue engineering: a review of spinning methodologies. Tissue Eng., v. 12, n. 3, p. 435-447, 2006.

Randhawa, R.; Bassi, P.; Kaur, G. In vitro, in vivo evaluation of inter polymer complexes between carboxymethyl fenugreek gum and chitosan or carboxymethyl guar gum and chitosan for colon delivery of tamoxifen. Asian Pac. J. Trop. Dis., S202-S207, 2012.

Tortora, G. J.; Derrickson, B. Principles of anatomy and physiology. John Wiley \& Sons, 13rd ed., 2012.

Veiga, I. G. Produção e caracterização de membranas de quitosana associada com outros biopolímeros para a liberação controlada de anti-inflamatórios; Tese de doutorado; Faculdade de Engenharia Química - Univ. Estadual de Campinas; Campinas, 2012.

Weller, C.; Sussman, G. Wound dressings update. J. Pharm. Pract. Res., v. 36, n. 4, p. 318324, 2006.

Woodruff, M. A.; Hutmacher, D. W. The return of a forgotten polymer -Polycaprolactone in the 21st century. Prog.Polym. Sci., v. 35, p. 1217-1256, 2010.

Agradecimentos: à CAPES e ao CNPq pelo apoio financeiro e à equipe do Laboratório de Recursos Analíticos e de Calibração (LRAC/UNICAMP) pelas análises realizadas. 